\title{
FACTORS ENCOURAGING AND HINDERING A WIDER ACCEPTANCE AND MORE FREQUENT UTILIZATION OF MOBILE PAYMENT SYSTEMS: AN EMPIRICAL STUDY AMONG MOBILE PHONE SUBSCRIBERS IN TURKEY
}

\author{
DOI: 10.17261/Pressacademia.2021.1455 \\ JMML- V.8-ISS.3-2021(3), p.164-183 \\ Ertan Coskun ${ }^{1}$, Murat Ferman² \\ ${ }^{1}$ Isik University, Contemporary Management Studies, Maslak, Istanbul, Turkey. \\ ertancoskun@hotmail.com ,ORCID: 0000-0002-2632-5829 \\ ${ }^{2}$ Beykent University, Maslak, Istanbul, Turkey. \\ muratferman@beykent.edu.tr, ORCID: 0000-0003-4019-0219
}

\begin{tabular}{l} 
Date Received: May 22, $2021 \quad$ Date Accepted: August 28, 2021 \\
\hline To cite this document \\
Coskun, E., Ferman, M., (2021). Factors encouraging and hindering a wider acceptance and more frequent utilization of mobile payment \\
systems: an empirical study among mobile phone subscribers in Turkey. Journal of Management, Marketing and Logistics (JMML), $8(3)$, \\
164-183. \\
Permanent link to this document: http://doi.org/10.17261/Pressacademia.2021.1455 \\
Copyright: Published by PressAcademia and limited licensed re-use rights only.
\end{tabular}

\section{ABSTRACT}

Purpose- This research deals with determining the factors that affect adoption of mobile payment technology among consumers, in Turkey. It seeks to find any patterns and connections that may be of aid in framing an implementation strategy for facilitating further adoption. It has gathered different definitions of "mobile payment" in literature and used a consumer side definition.

Methodology- A survey is conducted among mobile phone subscribers in Istanbul, Turkey for primary data collection phase of this research. Istanbul is the city that holds the biggest population and has the highest amount of mobile phone subscribers in the country. Istanbul's current population is more than 15.6million and mobile phone subscriptions are more than 22 million as of 2019 . Survey responses have been analysed with structural equation modelling and results are presented in the corresponding sections.

Findings- Empirical findings of the research show that factors such as usefulness, security, social influence, ease of use, enjoyment and innovativeness have positive effects on use of mobile payments among consumers. Factors such as attractiveness of alternatives and new technology anxiety have negative effects on use of mobile payments.

Conclusion- This research has shown that mobile payments are a potential mainstream trend for the near future. Several benefits of the mobile payment value chain for both technology providers and the consumers have been identified. Other findings of this research can be stated as the challenges which the stakeholders are experiencing while trying to extend mobile payment technologies to a wider consumer base. Therefore, the results and the variables can be used by service providers who want to launch new mobile payment solutions for similar markets and they can take actions for getting more efficient results accordingly.

Keywords: Mobile payment, mobile commerce, technology acceptance, technology adoption, structural equation modelling JEL Codes: L96, M31, O33

\section{INTRODUCTION}

Online shopping has become a strong alternative for traditional shopping as consumers can explore various alternatives that enable to choose the best for them. Moreover, online shopping enabled people to exceed the barriers of time and place. Because of online shopping, people do not need to hurry for catching closing time of shops or to wait for opening times anymore. Online purchases provide customers with delivery options too. This allows customers to be freed of carrying the goods they purchased. One of the crucial solutions for online financial transactions are the online payments. The centre of interest for this research is the technology acceptance and adoption of mobile payment systems among consumers.

Mobile payment adoption around the globe is increasing with time in general. Preventing the shadow economy by recording each transaction digitally is a major advantage for the government authorities to promote this technology. Avoiding the need for carrying cash and credit cards is a convenience for the consumers which in turn increases efficiency in daily lives. Each transaction of the consumer is easily accessible from the mobile device. This provides recalling of the financial transaction history as needed which is another convenience for the consumer. If we look from the viewpoint of network service providers and the financial institutions, mobile payment is a new service delivery channel that will create 
extra revenues. These are a few aspects supporting the adoption of mobile payments from the aspects of different stakeholders in this ecosystem.

However, research on mobile payments suggest that consumers' adoption rate is less than the expectations of the stakeholders. There are different reasons for this tardiness which are all independent from each other. One reason could be that mobile payment solutions were not mature enough and not very user-friendly, therefore they were not favoured by the consumers, merchants and financial institutions.

This research investigates the mobile payment acceptance and utilization issue from a consumers' perspective. It examines the factors that affect mobile payment acceptance in a specific time frame and in a particular region. Another unique aspect of this study is the time frame it takes place in. The research was conducted in the time of a pandemic when remote delivery and online purchases were widely preferred compared to offline alternatives. There happened to be lockdowns all around the city due to the COVID-19 virus pandemic for a few months between April 2020 and June 2020. Consumers could not go to shops physically. So, they had to use mobile devices and remote methods to fulfill their financial transactions that emerged from their online purchases. The factors will be gathered from the literature that focus on similar problems related with new technologies and their adoptions.

\section{LITERATURE REVIEW}

\subsection{Mobile Commerce Market Dynamics}

Internet and telecommunication (ICT) innovations in the recent years have produced new shopping ways. People can buy all sorts of products from anywhere, any time with their smartphones. This situation led to the increasing awareness of mobile payments compared to conventional types such as cash, debit cards and credit cards. Online shopping was pioneered by Michael Aldrich in the UK in 1979, and he launched two different systems: Business to Business (B2B) and Business to Consumer (B2C) (Devkishin, 2013). Mobile payments and mobile commerce encourage impulse buying. This is mainly because it removes the need for consumers to carry cash all the time. It helps the prevention of lost sales opportunities because of customers' lack of cash.

Mobile wallet solutions help businesses in building a more concrete relationship with their customers. Businesses can contact their customers at the optimum times and locations. They can make more personally segmented offers and gain better insights. This is much more efficient than conventional marketing channels. On the other hand, consumers can eliminate the need to carry cash and cards. They can benefit from the loyalty programs of merchants, track their spending. Consumers can also benefit from the security option with less theft and fraud possibility compared to cash and credit cards. Mobile payments are more secure, and easier than paying with credit cards. The sensitive information of customers and the transaction are stored in an encrypted cloud environment instead of a local mobile device. This prevents unauthorized access to personal information since the cloud server and database are protected by the mobile wallet service providers.

The rate of owning smartphones and mobile technologies keep increasing in emerging markets. However, mobile technology utilization is much higher in developed countries. More people living in developed countries have easier access to higher internet bandwidth and latest mobile devices (Poushter, 2016).

The rate of increase in internet accessibility for developing countries has been growing remarkably since 2013. The highest increase was recorded in Turkey according to a research conducted among 16 countries between 2013 and 2015. 41\% of the population had access to internet in 2013 in Turkey, whereas this increased to $72 \%$ in 2015 . At least $60 \%$ of the population have access to internet in developing countries. Smartphone ownership level is increasing in developing countries according to the same research. The rate of owning a smartphone among the population was $21 \%$ in 2013 whereas this increased to $37 \%$ in 2015 . South Korea has the highest internet accessibility rate with $94 \%$ of the population as of 2015. Australia comes next with 93\% and Canada with 90\% (Poushter, 2016). The research was published by Pew Research Centre in 2016.

Another aspect of internet access taken into account in the research is the education level difference of individuals. Internet access in the population is higher for people with higher education levels. This situation is present both for developed and developing countries. The difference is as high as $50 \%$ in some countries.

Income level also affects internet access and smartphone usage. There is a $51 \%$ difference between high income and lowincome individuals where the advantage is on the side of people with higher income. The highest rate of owning smart phones is in South Korea with $88 \%$ of the population. The rate in Turkey is $59 \%$ and its rank is 12 among all other countries in the world. Least rate of smartphone ownership is observed in Pakistan with $11 \%$, and $4 \%$ in Uganda and Ethiopia which have considerably low-income levels. There appears to be a direct link with higher income level and higher amount of smartphone ownership. 
The rate of increase in smartphone ownership is increasing rapidly in developing countries. Turkey is leading the increase among the countries that are investigated. The smartphone ownership rate was 17\% in 2013 in Turkey and has increased to $59 \%$ in 2015.

Gender is another factor that is considered. Difference in internet access and smart phone usage occur mainly in countries where gender discrimination is common. $48 \%$ of males have access to internet whereas only $29 \%$ of females have access to internet in Kenya. There appear to be differences among genders in Europe, in countries such as France, UK and Germany as well even if they are among developed countries (Poushter, 2016). Smartphone ownership among younger people is also more common than older people.

Mobile commerce and mobile payments are on the rise around the globe and in Turkey. The extensive usage of mobile banking by Turkish consumers helps the mobile commerce in Turkey a lot. According to the Mobile Banking 2016 survey by ING Bank, most consumers believe that mobile banking has a positive impact on their cash management, Turkish consumers agreeing with a rate of $85 \%$ which is the highest rate in the survey (ING Bank International Research, 2016).

Mobile shopping is another rising subject that is investigated within scope of this survey. $56 \%$ of smartphone owners in Europe responded that they will probably use mobile payment during shopping in the following year. $81 \%$ of Turkish respondents answered the survey similarly. Main reasons for this preference are the speed, convenience and the extensive usage possibility, respectively.

The conflict between mobile network operators and financial institutions on mobile payment revenue sharing still exists and this conflict slows down the development of mobile payment market. However, all stakeholders still see mobile payments as an alternative revenue channel. Mobile payments can extend its usage areas to parking, movie tickets, transportation tickets etc.

Japan, USA, Germany and the UK are among the leading mobile payment markets around the globe. China is another leading market with Alipay and Wechat Pay apps which are being used by consumers for sending money to peers and making payments. Turkey and Romania are the emerging markets in Europe that have a high trend in mobile payments.

Turkish population is a mobile friendly market with a high rate of mobile payment preference whenever possible. There appears to be a lot of new product development for mobile payment as well. Examples are Papara, Ödeal, Paycell, Payguru etc.

The number of mobile subscribers in Turkey is over 80 million by 2018 which is $99 \%$ penetration among total population of the country. This is a very strong sign that payment market is going to be develop around mobile devices.

\subsection{Diverse Mobile Payment Definitions}

Considering the substantial utilization areas of smart phones and vast numbers of available mobile devices around today, it is not a surprise that smart phones are able to be commonly used as a financial transaction device. Especially the telecommunications companies are searching for methods to enhance revenues by moving into alternative business areas since revenues have diminished in voice, SMS and data areas compared to past. Telecom network operators are trying to provide consumers with solutions that let them purchase goods and services via smart phones (Dornan 2001).

Using the mobile phones for carrying out financial transactions depends on effective mobile payment solutions. Essential parts of the mobile commerce ecosystem are the mobile payments. Without the financial transaction, no commerce action would be complete. However, no standard mobile payment system has yet been accepted by all parties involved. This is one of the main reasons that prevents the prevailing mobile commerce activities (Carlsson 2001; Kruger 2001).

There are various definitions for the mobile payment concept in the literature. These definitions are all similar to each other one way or another. They all involve a mobile device, a financial transaction and a confirmation process.

Payment by phone (mobile payment) is a vital process of mobile commerce, and it designates "any payment where a mobile device is used to initiate, authorize and confirm an exchange of financial value in return for goods and services (Au and Kauffman, 2006)."

Mobile payments might as well be defined as; "the electronic payment transaction procedure that enables a payer to use a mobile device to initiate, authorize or confirm a payment" (Yoris, et al., 2008). Therefore, mobile payments provide buying of products and services including the fund transfers between bank accounts of the business and the customer.

Another definition for mobile payments is, "payments that are carried out via the mobile phone (Kruger 2001). Shon and Swatman's definition for an online payment solution is "any conventional or new payment system which enables financial transactions to be made securely from one organisation or individual to another over a mobile network" (Shon and Swatman 1997)." 
Mobile payments are payments for products, services, and bills/invoices with a mobile device (such as a mobile phone, smart-phone, or tablet) by taking advantage of wireless and other communication technologies (such as mobile telecommunications networks, or proximity technologies) (Antovski and Gusev, 2003; Ding and Hampe, 2003b).

From a broader view, a mobile payment is a payment in which a mobile device is utilised to perform a transaction or a transfer of funds in return for purchases (Karnouskos and Fokus, 2004).

Businesses are developing diverse mobile payment applications for their customers in an increasing manner. Solutions like Samsung Pay, PayPal, Wechat Pay, Apple Pay, Alipay, and Google Wallet are being used frequently all around the world and are gradually taking over conventional payment methods such as cash, debit and credit cards. Local applications in Turkey such as BKM Express, Paycell and Fastpay are also becoming increasingly widespread among Turkish consumers. This shift will disrupt how people transfer and receive money, that might bring about a cash-less globe in the future.

Mobile payment systems enable fast, basic and somewhat inexpensive fund transfers. Individuals are able to pay bills, invoices, purchase goods, book flights, pay parking fees, taxi fares and buy various other stuff using their mobile devices. Payments at ticketing and vending robots and at sales points with attendants are also possible Its benefits include the convenience of $7 / 24$ access to payments by the merchants as well.

Credit cards are the most common tools used for conventional payments. These plastic cards can be used in e-commerce and electronic payments via entering its numbers and other required information on the payment platform. A virtual card can also be used in e-commerce which is connected to the main credit card and has a limit specific to the respective purchase. Virtual cards are useful for securing the customer from frauds since the usage limit can be reset after each purchase.

Mobile payments remove the dependency of credit cards and cash. Consumers can track their spending and invoices via their smartphones easily. They can also receive personally tailored discounts, promotions and campaigns from brands.

From merchants' point of view, disruptive technologies such as mobile payments help businesses manage their cash flows more efficiently than conventional methods. In cases with large amount transactions, clearing period is bypassed and related costs are reduced. Paper usage is reduced which helps sustainability and is more environment friendly.

Small-sized businesses that run mostly on cash get a chance to provide customers that do not carry cash with an alternative payment solution. This increases customer loyalty and sales opportunities are not missed due to lack of cash. It also helps the business get a better position compared to its competitors.

Mobile payments provide various advantages; however, the shift from conventional methods to mobile payments needs time. The society's approach to mobile payments is a crucial research topic and technology solution providers and merchants' expectations should cohere for mobile payments to be adopted by consumers.

\subsection{Mobile Payment Technology Acceptance Challenges}

Mobile payment solutions compete with other sophisticated physical and electronic payment solutions. As smart phones are becoming the main device for online commercial activities, the potential for mobile payments to overtake traditional payment methods is becoming more probable in the near future. However, service providers are still striving to widen the acceptance of mobile payment solutions.

Adoption and consumer acceptance topics are covered in some of the published mobile payment studies in literature. This is an essential issue for all the parties involved in mobile payment ecosystem. Technology service providers, merchants and consumers are all associated with it. A successful adoption of mobile payment systems depends on various factors. These factors reflect either the user's or the merchant's or service provider's view.

A research conducted by Visa in the United Kingdom in 2016 analysing the mobile consumer profile found that more than $70 \%$ of the consumers utilize their smart devices for financial transactions.

A study that focuses on effectiveness criteria of online payment systems brought out fifteen factors distributed among stakeholders. Reliability and security were crucial for the stakeholders. Reduced transaction rates were substantial for consumers, businesses and banks. Scalability was important for network providers and flexibility was also crucial for businesses (Shon and Swatman, 1997).

A research investigates the Mondex solution, which was offered as a replacement for cash in 1990's developed by Mastercard. The agents that affect the prosperity of this payment solution are not in case product's gains will surpass the development costs estimating it is commonly used, but rather user and business adoption, channel coordination. Prosperity of payment solutions is related with reaching a critical mass of merchant and consumer acceptance. This is closely tied to how universally available the payment solution is in the market (Clemons, Croson et al. 1997). 
A study conducted by Jayawardhena and Foley states that any online payment system should meet some requirements in order to succeed. These are mainly related to cost, ease of use, exchangeability and universality, security requirements such as privacy, anonymity and trustworthiness. Other requirements are listed as regulatory framework, integration with backend systems and support (Jayawardhena and Foley, 1998).

Changes in telecommunication technologies, social/cultural and regulatory environment along with competition in financial services market leads to new advances in payment solutions payments (Javalgi and Ramsey, 2001).

People's buying behaviour and consumption styles change along with changes in their social and cultural environment. People tend to look for new payment offers as they become more mobile. There are cultural reflections on payment preferences as well. Debit cards are more commonly preferred compared to credit cards in Europe whereas it is vice versa in US (Bohle and Krueger, 2001).

Introduction of new technologies in telecommunications industry have influenced the mobile payment solutions. Development of bluetooth, infrared, RFID and NFC technologies led to the introduction of new mobile payment options (Zmijewska, 2005).

Legal and regulatory structures of different regions affect the requirement of standardization for payment solutions. Financial activities amidst distinct countries are especially complicated because of different financial regulations among governments. This situation may be overcome by unifying the regulations among a group of countries such as the European Union.

These issues all create compelling influence on the acceptance of mobile payments. However, these factors are all beyond the control of the stakeholders in mobile payment industry.

Four main factor groups are identified in a research by Bohle (2000) on the outlook of retail online payment systems that are related to demands of different parties involved. These factors are regulations, standardisation, security, and integration of payments into online transactions.

Another study that investigates whether an online payment system will be widely accepted and lists the factors that will affect this matter. These factors are stated as divisibility, independence, ease of use anonymity, transaction fees, interoperability and security. Payment system's requirement of how much specialized hardware and software it needs is the independence factor. Interoperability is defined as how a payment system integrates with other infrastructure that is already available. Online payment systems must secure the transaction between the merchant and the consumer. Divisibility is the payment amounts supported by the system. Effort put by the user to perform the transaction is stated as ease of use. Transaction fee is the commission taken from the business and the mobile payment user for a successful transaction (Turban, King et al. 2002).

This research mainly focuses on factors that fall within the consumer's view. Consumers create the demand for mobile payment solutions and lead its success by using it. Therefore, adoption success depends on the number of users and transaction volumes. However, consumers do not have the direct impact to steer the development of innovations at service providers' side at the early stages. Business requirements and improvements have more effect on solution developments since there are a limited number of users at the early stages. This increases the failure risk of the newly introduced payment solutions.

Merchants have crucial importance in mobile payment adoption and development. They facilitate the industry for technology solution providers and financial institutions. It is rather very difficult for a payment solution to be commonly used unless merchant promotion is available. A mobile payment solution can easily be rejected if it does not suit the business conditions of the merchants such as high commission fees. It is also possible for merchants to provide their own mobile payment solutions and promote them. Starbucks mobile app is an example with built-in payment options and customer loyalty features.

Cash, debit and credit card payment options are still more preferred compared to the more digital alternatives in Europe. The only exception is the Scandinavian countries. Mobile payment solutions have emerged mainly due to the need for a payment solution to assist mobile commerce. Similarly, bill payments have moved to mobile payment platforms due to the developments in internet banking solutions. Some trends consider mobile payments as just an alternative channel for current payment market, whereas there is a compromise which mobile payments are a potential threat to conventional payment types with the entrance of mobile payment operators into the market.

Results of a research conducted in the Swiss market indicated that traditional card payment methods were preferred over mobile payments (Ondrus and Pigneur, 2005). Another study showed that mobile payments would be used to complement existing traditional payment methods (Dahlberg and Mallat, 2006). 
It is discovered in a research that the biggest concern of smart phone users who do not use mobile payments was the security risk. Consumers thought saving their credit card information in their smart phones was more open to theft than having their credit cards stolen from their wallets (Huh et al. 2016).

A similar research that was carried out by Creative Strategies Incorporation (CSI) found that trust was the main barrier for mobile payment consumer acceptance. Therefore, biometric technology along with pin codes and one-time passwords were suggested to be used as additional layers of security, so that consumers would feel more secure and be more willing to use mobile payment systems (Weiss, 2011).

Although there are laws that cover the mobile payments from the aspect of financial services, there still exists a remaining question if the regulations are adequate in providing high protection to consumers. This issue is considered because mobile wallets and payment solution providers are applications for realizing the technical aspects of mobile payments and they are not the financial service providers (Lowry, 2016).

There have been some attempts to accelerate the acceptance of mobile payment solutions by giving incentives to users. Financial institutions and merchants compensate the incentives in developing countries so that their services become more efficient and reduce the usage of traditional payment methods via ATMs and physical branches which are more costly (Alexandre et al., 2011). The reason why this method works in developing countries is the lack of high-quality traditional payment services. In developed countries, even if a big latent exists for mobile payments in the market, people see the traditional methods safe and do not want to switch. However, in poor countries, people feel insecure with cash and credit cards because of the high fraud and theft risk. This leads to a choice of more innovative, more secure mobile payment solution by the consumers. More preference of mobile payments instead of cash shifts the unrecorded financial movements to a formal, recorded area.

Mobile payment solutions that are available mostly require a separate app to be installed on users' smartphones. Unless a universal standard is built by the stakeholders, users will resist fully adopting mobile payments. Otherwise, if standards are finally accepted by all stakeholders, consumers will enjoy mobile commerce independent of country borders and the process will be much more simplified.

It is rather difficult for technology service providers to develop the perfect mobile payment solution that will suit all the needs of users, besides merchants and the regulators. There exist diverse aspects on acceptance of mobile payment solutions listed in the literature that have been identified during the pursuit for a perfect mobile payment system.

Infrastructure limitations, security, and absence of standards are the main aspects affecting mobile payment acceptance in the research based on existing studies on mobile payments by Diniz $\mathrm{H}$ et al., (2011). The study focuses on the limitations that prevent mobile payments from being widely adopted. It states that user acceptance aspects are generally related to trust, privacy, security, risk perception and fraud. the study mentions the emotional hurdles brought about new technology anxiety too.

There exists a rise in the number of papers published on mobile payment research over the years. It is studied in a wide range of locations and countries. China, Germany and Spain are among the leading countries.

Technical and security standards must be superior for a prevalent usage and consumer acceptance of mobile payments. Privacy must not be a matter of concession and there must not be any chance of monetary damages for users. On the other hand, customer authentication is a vital issue for merchants who are providing mobile payment services to customers. Integrity and confidentiality must be assured by the technology solution providers (Misra and Wickamasinghe, 2004).

Even though mobile payment solutions are available for a decade now, they still lack the technology standards that will provide a universal payment solution. Standards integration for mobile commerce is crucial and this is going to let solution providers and users to invest more on this matter to produce more value. Lack of standardization causes several fragmented and domestic varieties of mobile payment solutions developed by distinct companies. Some solutions are bank centred whereas the others are mobile network operator centred depending on the business models.

Standards have to ensure the trust, privacy and security matters for users along with the joint working between several solutions. Standardization is a course of cooperation among all related parties. It is a legislative and commercial negotiation rather than a theoretical debate. There are some widely accepted models in the market that are settled by the first movers. These early solution providers have come up with standards proposals hoping to set them default using their early mover commercial benefit. However, there is no consensus among different solution providers and governments in terms of mobile payment standards setting (Lim, 2007).

Regulations for the companies in the banking business are distinct from those controlling the communications business. Therefore, it is a major challenge for the regulatory authorities to standardize the regulations that suit all the parties involved in mobile payments. 
Collaboration between telecommunication network solution providers and banking establishments on mobile payment solutions is limited since both stakeholders are trying to control bigger share in the value chain to boost their revenues. Nonetheless, traditional payment solution providers are possibly going to adapt their operations to the mobile payments and a new payment channel will become commonly available as network providers support mobile payment solutions by providing the infrastructure. Some new mobile payment services also arise where banks and network service providers both get to support the business model as enablers.

Lack of an ideal business model is an obstacle on the service provider and merchant side of the mobile payment acceptance issue. Even though various business models are available in the market, they are all developed considering the interests of different stakeholders. No standard business model is accepted by all so far. The essential cause for this situation is the distinct interests of various merchants, service providers and regulation authorities which is mainly the government.

Operations management, agents in merchant stores and resellers are not fully compatible with mobile payments due to lack of standards, clear commission structures and ideal business models accepted by all parties in the ecosystem. These obstacles prevent the easy adoption of mobile payment systems among agents. More trainings are required for the agents to facilitate the wide spread of such innovative payment solutions.

High service availability and coverage are also concerns for the consumers and merchants. Mobile payment option might not be available all the time everywhere. Therefore, peers who are about to make the transaction might have to look for alternative ways for payment during their commerce. Lack of training of the agents might also affect the service availability for mobile payment solutions on the business side. Agents might look for easier methods for performing the payment transaction since they are not highly familiar with the mobile payment process.

Price and in other words, cost of the service is another concern for acceptance of mobile payment technology. Consumer side is interested in the price of the devices and services and financial initiatives whereas the merchant side is interested in commissions and financial sustainability of the initiatives.

It seems that costs, security, infrastructure and reliability are the main aspects which determine mobile payment acceptance. Nonetheless, mobile payment acceptance level is also affected by the socio-economic factors in the market such as regulations, previous user habits and readiness of the economy. It is also worth mentioning merchant characteristics and location of a market when discussing the mobile payment acceptance systems according to the research carried out in literature.

Mallat performed a qualitative research in 2007 on mobile payment adoption. There appeared some compatibility issues regarding larger amount of transactions during the focus group interviews. Users were fine with making payments not more than $€ 100$ using their mobile phones. They were concerned about security of their payments beyond this value.

Users also complained about the complexity of mobile payment services and mentioned this as a concern that would prevent further adoption. They mentioned the lack of information to complete the transaction in cases where an SMS is used and the large amount of time a user needs to enter payment codes (Mallat, 2007).

Users mentioned that the number of merchants offering mobile payment option is very limited. They are also concerned that there may appear to be hidden costs associated with mobile payments. Therefore, users were not willing to use the mobile payment option if the cash payment option was already available (Mallat, 2007).

The evidence in Mallat's research also indicated that trusting businesses and solution providers decreased the risk perception for mobile payment solutions. Users became keener to perform mobile payment transactions which involved credible banks, well known technology service providers and telecom operators. Payment solutions that involved banks were more favoured compared to other solution providers (Mallat, 2007).

Existing research studies on mobile payment acceptance in literature focus on case studies, literature reviews, experiments, focus groups, interviews and surveys. This research aims to use a survey performed in Istanbul, Turkey as main source of data. This form of examination on mobile payments may provide new insight, patterns and unbiased results on this topic.

\section{DATA AND METHODOLOGY}

Literature review is conducted by identifying the keywords and the research questions. Various research databases are searched according to the keywords and mobile payment adoption. An initial research model is formed using technology acceptance model.

Independent variables are gathered from the literature and previous research papers. The research model is modified according to these variables. Quantitative methodology is used for the statistical analysis of the surveys. Interpretations are made according to the statistical results. A measuring instrument is prepared for factor analysis of mobile payment acceptance. Results are evaluated using SPSS and AMOS software for statistical analysis. 


\subsection{Research Model and Hypotheses Development}

Proposed Research Model that describes the relationships between variables are shown in Figure 1 below. Constructs regarding mobile payment acceptance that are used in this research are arranged by the method utilized by Amoroso and Watanabe (2011). These constructs are gathered from technology acceptance model (TAM) that measure consumers' tendency to use mobile payment solutions. Technology Acceptance Model is the basis for this study.

A mobile payment adoption framework based on technology acceptance model was developed using eleven consumer related variables (Amoroso and Watanabe, 2011). These variables are; perceived ease of use, perceived usefulness, attitude toward using, facilitating conditions, social influence, perceived risk, perceived security and privacy, trust, perceived value, attractiveness of alternatives, behavioral intention to use.

\section{Figure 1: Proposed Research Model}

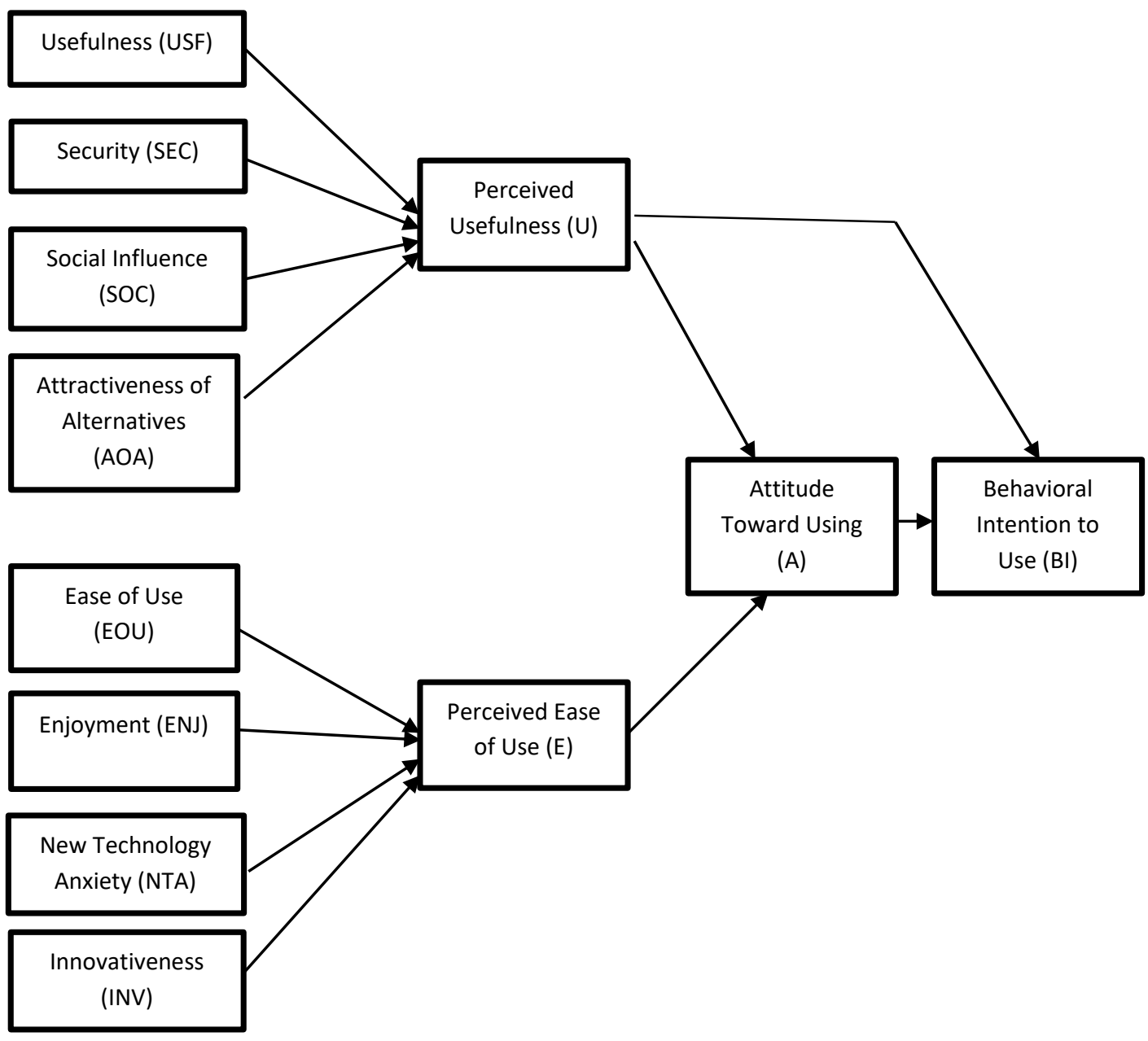

\section{Constructs for Perceived Usefulness}

Usefulness: The extent to which an individual thinks that using a mobile payment solution will increase the job performance" including technical elements such as smartness, responsiveness, availability, quality of the system and speed. (Davis, 1993). Incentives are also considered a part of usefulness in this research which are, events or objects independent of the user that can provoke action. Network service uptime is considered a part of usefulness within the scope of this research.

H1: Higher level of usefulness (USF) has a positive effect on use of mobile payment systems.

Security: The extent to which a mobile payment user feels secure by using a mobile payment solution or sending private information over a mobile payment system" (Shin, 2009). 
Uncertainty in newly introduced technologies leads to privacy and security concerns amidst users. Concern of personal and financial information theft might deter consumers from using mobile payments. The more security concerns the users have, the longer its acceptance will take (Yang and Forney, 2013).

The perceived security and risk vary among different markets. People might feel safe in countries where crime rate is low, whereas users might have a higher security concern in countries in which thefts and cyber frauds are more common. Extra authentication layers such as biometric fingerprint and face recognition technologies can be used in mobile payment solutions in high-risk markets (Wang et al., 2016).

Trust is considered as the assumption that merchants will execute activities considering customer expectations. Mobile payment users are also believed to think in a similar manner and this factor will affect the acceptance of mobile payments among consumers (Amoroso and Watanable, 2011).

Perceived risk is the perception that a service will cause loss when it is used. Users might feel the risk of experiencing a loss if they share their personal and financial information via a mobile payment solution. Risk perception is decreased as trust and security perception for the service is improved (Amoroso and Watanable, 2011). Implementing extra security layers and setting upper limits for transactions reduce the fraud potential therefore diminishing the perceived risk of mobile payment solutions. The extra precautions build a positive attitude, trust and therefore a higher behavioral intention to use mobile payments.

Feeling secure, risky or trusting the solutions are considered as complementary issues within the extent of this research.

H2: Higher level of security (SEC) has a positive effect on use of mobile payment systems

Social Influence: The extent to which a person thinks that important people around consider the new technology is worth being used by him or her.

This factor is named as "subjective norm" in the variables of UTAUT model. It basically relates to how a group of people in the environment influence a single user's behavioral intention to use a new innovation and how this perception reduces the uncertainty and risk concerns (Fishbein and Ajzen, 1975).

Satisfied users tend to act as advocates for a new technology. They make sure more people around them get to benefit from the new experience and help their peers with the potential risks.

H3: Higher level of social influence (SOC) has a positive effect on use of mobile payment systems.

Attractiveness of Alternatives: It is the presence of substitutes in the market. It evaluates the extent to which the substitutes influence the consumers' intention to use a new technology (Shin, 2009).

Mobile payment solutions have been around the market for years now. However, they still have strong rivals with an established network such as card-based payments and the conventional cash payments. These alternatives prevent mobile payment solutions to be extensively adapted. A switching cost appears in terms of convenience for consumers trying to use the innovative mobile payment solutions instead of more common methods.

The perceived value of mobile payments is the compensation of what users give up like time, opportunity cost, effort, price, cost and the benefits received in return. In other words, it can be described as a difference between what customers pay for a service and what they were willing to pay at first (Amoroso and Watanabe, 2011).

Usage cost is the expense that must be spent for using mobile payments and the necessary tools such as the mobile devices to be acquired to be able to use the technology.

Perceived value and usage cost are considered as a part of attractiveness of alternatives construct within the context of this research.

H4: Higher level of attractiveness of alternatives (AOA) has a negative effect on use of mobile payment systems.

\section{Constructs for Perceived Ease of Use}

There is an agreement between researchers that perceived ease of use affects the usefulness, attitude, behavioral intention and actual usage of a new innovation (Chau, 1996). Chau discovered that it is probable for people to refuse a new innovation if it needs perpetual exercise of knowledge, even if the same aspect will not substantially influence their behavioral intention to adopt it in the future once the technology is established (Murthy and Mani, 2013).

Ease of Use: the extent to which an individual thinks that using a specific technology will be effortless" (Davis, 1989). Compatibility is also considered as a part of this construct, which is "the extent to which a new technology is perceived as being coherent with the prevalent values, necessities, and past experiences of latent users" (Rogers, 1995). 
H5: Higher level of ease of use (EOU) has a positive effect on use of mobile payment systems.

Enjoyment: The fun or entertainment gotten by using a new technology" (Venkatesh et al, 2012) (Oliveira et al, 2016).

H6: Higher level of enjoyment (ENJ) has a positive effect on use of mobile payment systems.

New Technology Anxiety: The user's worry or concern of, adopting, or thinking of using a new technology" (Venkatesh, 2000) (Bailey et al, 2017).

H7: Higher level of new technology anxiety (NTA) has a negative effect on use of mobile payment systems.

Innovativeness: The extent to which an individual's eagerness or enthusiasm to try a new technology (Slade et al, 2015). Knowledge is also considered as a part of this construct, which is the degree of acquired awareness or information by experimenting or education on a new technology.

H8: Higher level of innovativeness (INV) has a positive effect on use of mobile payment systems.

Attitude: The total of beliefs about a specific behavior scaled by assessment of those beliefs" (Davis, 1993).

Attitude toward using evaluates the positive or negative feeling of a person among using a new technology. Fishbein and Ajzen (1975) discovered that a person's judgment on adopting or not adopting a new technology depends on that individual's positive or negative opinions on adopting that specific innovation.

H9: Higher level of attitude (A) has a mediating effect on intention towards mobile payment technology acceptance.

Behavioral Intention: The role of attitudes regarding a behavior which has been discovered to foresee actual behavior (Davis, 1993).

It is a user's inclination to act in a specific manner that designates actual usage of a technology. Behavioral intention (BI) is negatively affected by "new technology anxiety" and "attractiveness of alternatives" factors (Yang et al., 2012).

\subsection{Data Collection and Sampling}

A survey is prepared to measure the effects of the constructs listed above. Google Forms is employed for the technical development. There are two sections in the survey. First section gathers information on respondents' demographic status and mobile payment usage level. Second section consists of questions that are gathered and modified from the literature. Survey is performed in Turkish since the respondents are all Turkish speaking individuals. There is an introduction section about the research goal just before the questions.

Sample size mean for analysis in previous studies is 465 . Sample size median is 292. Research with highest sample size is 2587 (Liébana-Cabanillas et al, 2018). Technology adoption studies are mostly carried out with university students since this is a rather easier task. Although reaching out to schools is faster and cheaper, getting the sample from university students cannot represent the population.

This research uses a wider range of sample size. A sample of 685 respondents located in Istanbul for this study from age groups of $18+$ and all education levels are comprised among the survey.

To have a generalizable result after data collection, population is considered as "the smart phone using mobile phone subscribers in Istanbul, Turkey".

First section of the survey collects demographic information such as respondent's mobile operator, city, age, gender, education level, monthly income, how long and how often the respondent engages with mobile payment.

Second section of the survey questions will be in a 5-point Likert Scale as; Strongly Agree (5), Agree (4), Undecided (3), Disagree (2), Strongly Disagree (1).

Data is collected via convenience sampling method between 26.04.2020 and 05.05.2020. The survey URL is provided to the respondents via whatsapp, linkedin, facebook messages for them to fill and share with their social / professional network.

Total of 685 relevant surveys are collected from mobile phone subscribers located in Turkey, in Istanbul. 14 surveys that are out of scope of this research that are identified according to the answers for demographic questions are removed from the data set.

112 respondents out of 685 who have not used any mobile payments to date have been included in data analysis since this group was aware of the technology and did not use it deliberately either because of security concerns or did not prefer mobile payment method as regards to other type of payments such as credit cards or cash. 
The highest number of subscribers belongs to the Turkcell mobile network operator (54.3\%). This is expected as Turkcell has the highest market share in the region. However, this might cause a bias in our findings since mobile operator subscriptions are not equally distributed. Age group with highest frequency is "30-39" (36.8\%). However, "60+" age group has a slight weight in the sample. Female and male respondents' ratio is almost as the same with the population considered. The sample is skewed to "Bachelor's Degree or more" in education level.

Table 1: Main Characteristics of the Sample

\begin{tabular}{|c|c|c|c|}
\hline Demographic & Value & Frequency $(\mathrm{N}=685)$ & Percent \\
\hline \multirow{2}{*}{$\begin{array}{l}\text { Mobile Operator } \\
\text { Subscriptions }\end{array}$} & Turk Telekom Mobil (Avea) & 136 & $19.9 \%$ \\
\hline & Turkcell & 372 & $54.3 \%$ \\
\hline \multirow{3}{*}{ Age Groups } & $18-29$ & 152 & $22.2 \%$ \\
\hline & $30-39$ & 252 & $36.8 \%$ \\
\hline & $-60+$ & 17 & $2.5 \%$ \\
\hline \multirow{2}{*}{ Genders } & Female & 308 & $45 \%$ \\
\hline & Male & 377 & $55 \%$ \\
\hline Education Levels & High School and below & 120 & $17.5 \%$ \\
\hline
\end{tabular}

\section{FINDINGS AND DISCUSSIONS}

Quantitative analyses and results are given below. Sample properties, duplicate data handling, Structural Equation Modeling (SEM) assessment, statistical results of the models are provided.

Microsoft Excel is used for data handling. SPSS is employed for Cronbach's alpha and factor analysis. AMOS software is employed for structural equation modeling algorithm.

\subsection{Reliability and Factor Analyses}

Cronbach's Alpha is calculated as 0.714 . This leads to the outcome that the internal consistency reliability conditions are met.

Exploratory factor analysis is the first one in the overall analyses. Questions regarding each of the eight constructs have been analysed in SPSS via exploratory factor analysis. The goal of this analysis was to observe if our constructs are well suited with the questions asked in the survey.

The first step of the factor analysis is the Kaiser-Meyer-Olkin (KMO) Test. It is executed to see whether the data is appropriate enough for factor analysis. The test result is 0.756 which should not be less than 0.6. Therefore, factor analysis can be run. Factor analysis for independent variables demonstrates that all factor loadings are above 0.5 and the lowest is 0.685. The questions in the survey are well grouped similar to the previous studies in the literature review. The factor structure that is formed according to the modified research model is parallel with the models reviewed in the literature. The survey questions are found to be well chosen for the constructs.

Kaiser-Meyer-Olkin (KMO) Test is performed to see if the dependent variables data is appropriate enough for factor analysis. The test result is 0.713 which should not be less than 0.6 . Therefore, factor analysis can be run for the dependent variables. Factor analysis for dependent variables table above demonstrates that all factor loadings are above 0.5 and the lowest is 0.855 . The questions in the survey for dependent variables are well grouped too. The EFA results show a well grouping structure of the questions. The survey questions are found to be well chosen for the constructs.

\subsection{Structural Equation Modelling}

Research model is examined with statistical analyses. Then first proposed research model is examined using path analysis. Research model is changed according to the results and final research model is tested again and exhibited.

Structural Equation Modelling (SEM) is adopted for analysing the structural model of the factors. AMOS software is used for this analysis. Covariance based SEM is more useful for theory testing and confirmation. Covariance based SEM is used for this research for theory testing and confirmation. 
Figure 2: Initial Research Model

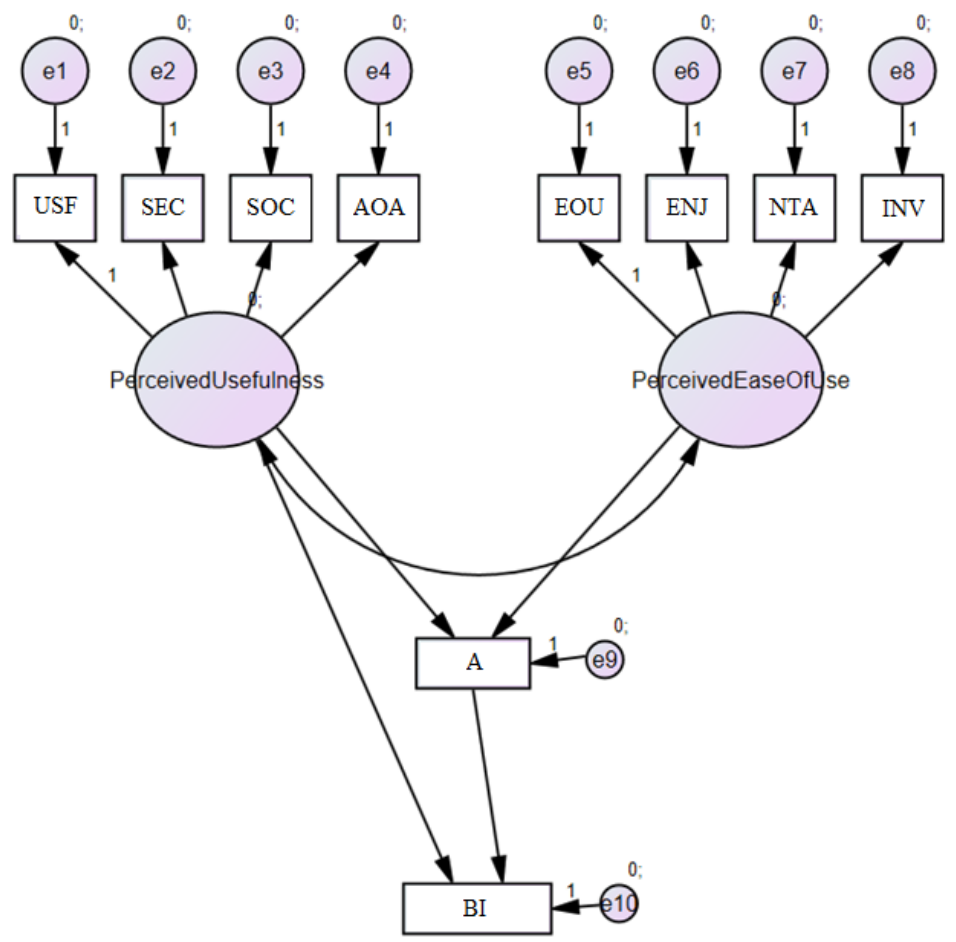

Initial test results indicate that chi-square value for the initial model will significantly improve if e8 and e10, e2 and e3 are correlated.

Table 2: Covariances

\begin{tabular}{ccc}
\hline Modification Correction & Modification Index (M.I.) & Change Ratio \\
\hline e8 $\rightarrow$ Perceived Usefulness & 4.18 & 0.012 \\
\hline $\mathrm{e} 8 \leftarrow \rightarrow \mathrm{e} 10$ & 45.129 & 0.141 \\
\hline $\mathrm{e} 6 \leftarrow \rightarrow \mathrm{e} 10$ & 4.781 & -0.049 \\
\hline $\mathrm{e} 5 \leftarrow \rightarrow$ Perceived Usefulness & 5.53 & -0.015 \\
\hline $\mathrm{e} 5 \leftarrow \rightarrow$ Perceived Ease of Use & 5.027 & 0.015 \\
\hline $\mathrm{e} 5 \leftarrow \rightarrow \mathrm{e} 9$ & 5.831 & 0.064 \\
\hline $\mathrm{e} 5 \leftarrow \rightarrow \mathrm{e} 10$ & 8.22 & -0.069 \\
\hline $\mathrm{e} 4 \leftarrow \rightarrow \mathrm{e} 8$ & 4.084 & 0.043 \\
\hline $\mathrm{e} 3 \leftarrow \rightarrow \mathrm{e} 10$ & 4.688 & -0.052 \\
\hline $\mathrm{e} 3 \leftarrow \rightarrow \mathrm{e} 6$ & 8.364 & 0.074 \\
\hline $\mathrm{e} 2 \leftarrow \rightarrow \mathrm{e} 6$ & 14.837 & 0.117 \\
\hline $\mathrm{e} 2 \leftarrow \rightarrow \mathrm{e} 3$ & 39.638 & 0.201 \\
\hline $\mathrm{e} 1 \leftarrow \rightarrow \mathrm{e} 8$ & 10.579 & -0.065 \\
\hline $\mathrm{e} 1 \leftarrow \rightarrow \mathrm{e} 3$ & 4.94 & 0.05 \\
\hline
\end{tabular}

Modification indices indicate how much the model fit would improve if the parameters were free instead of constrained.

Modification index between e8 and e10 is 45.129 . Modification index between e2 and e3 is 39.638 . These values show a serious evidence of misfit.

Following results are found after the model is run with AMOS software. 
Figure 3: Final Research Model

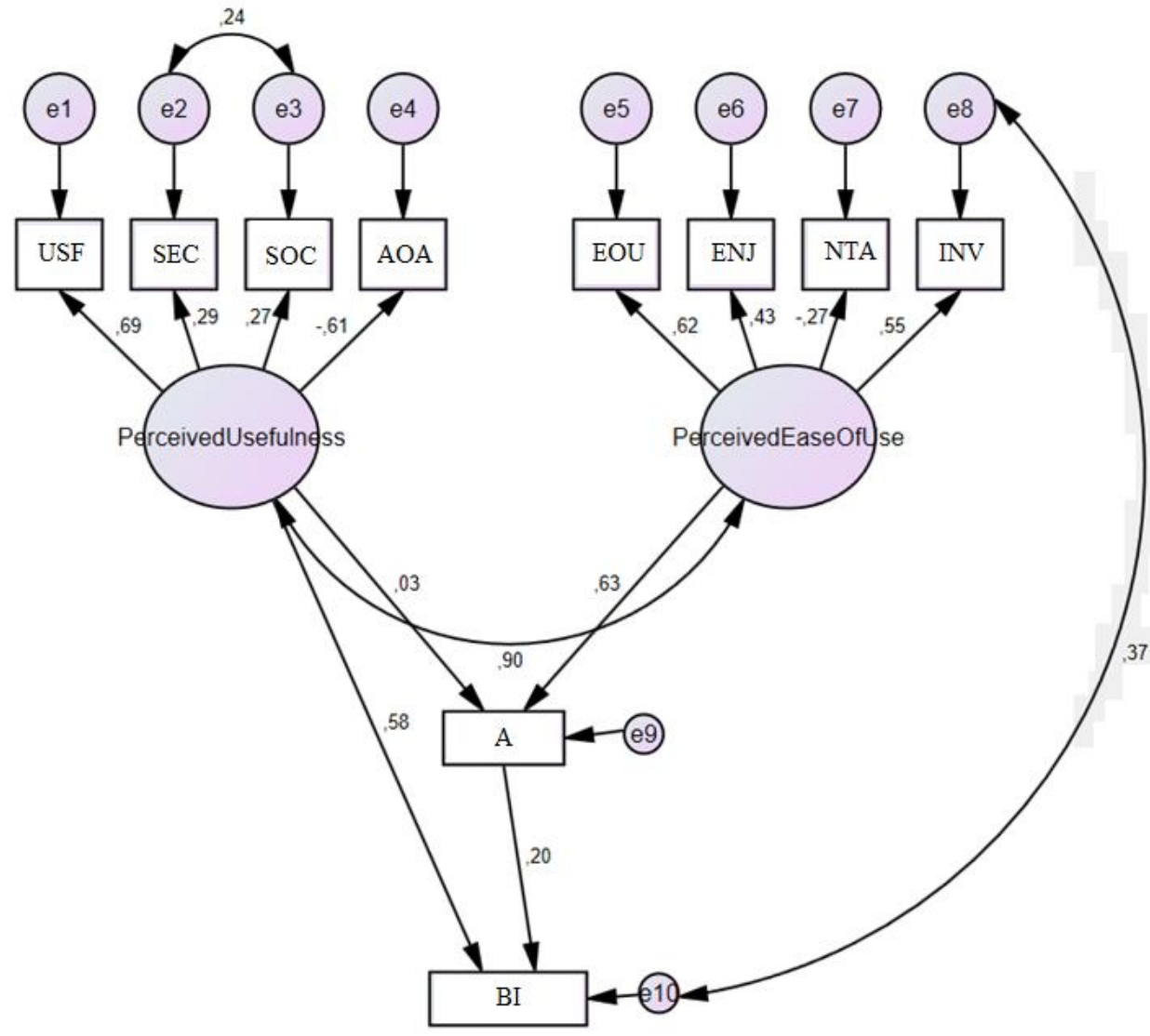

\section{General Model Fit}

Chi-square goodness of fit test result gives a way to decide if the data values are a "good enough" fit to the model. $\chi 2 / D F$ value to be lower than 3 is a sign for a good fit.

CMIN shows the chi-square values (1.563) are lower than 3, therefore test indicates a good fit with the data and the model.

Table 3: General Model Fit

\begin{tabular}{lccccc}
\hline & NPAR & CMIN & DF & P & CMIN/DF \\
\hline Default Model & 35 & 46.878 & 30 & 0.026 & 1.563 \\
\hline Saturated Model & 65 & 0 & 0 & & \\
\hline Independence Model & 20 & 1466.168 & 45 & 0 & 32.582 \\
\hline
\end{tabular}

$\mathrm{X}^{2} / \mathrm{DF}=1.563 \leq 3$

\section{Compared Fit Indices}

Normed Fit Index (NFI): It rescales the Chi-square value of the proposed model between 0 and 1 and compares it to a statistically meaningful benchmark. It is designated as Bentler-Bonett Normed Fit Index as well, NFI is an incremental calculation of goodness of fit for any statistical model that is not influenced by the number of factors in the model. An NFI of 0.95 , shows the model improves the fit by $95 \% .0 .968$ is the calculated value for NFI and this shows a good fit. NFI value higher than 0.90 usually represents an acceptable fit.

Incremental Fit Index (IFI): IFI has a value between 0 and 1. Model fit increases as IFI value is closer to 1, over 0.90 is a good fit, but it can exceed 1. 0.988 is the calculated value for IFI in this study and this shows a good fit. 
Comparative Fit Index (CFI): CFI is an altered form of NFI. It is not quite sensitive to the sample size. It compares the fit of a target model to the fit of a null or independent model. CFI value that is over 0.97 is a good fit. 0.988 is the calculated value for $\mathrm{CFI}$ in this study and this shows a good fit.

\section{Baseline Comparisons}

Table 4: Baseline Comparisons

\begin{tabular}{lccccc}
\hline & NFI & RFI & IFI & TLI & \multirow{2}{*}{ CFI } \\
\cline { 1 - 5 } & Delta1 & Rho1 & Delta2 & Rho2 & \\
\hline Default Model & 0.968 & 0.952 & 0.988 & 0.982 & 0.988 \\
\hline Saturated Model & 1 & & 1 & & 1 \\
\hline Independence Model & 0 & 0 & 0 & 0 & 0 \\
\hline
\end{tabular}

$0.95 \leq \mathrm{NFI} \leq 1,0.95 \leq \mathrm{IFI}, \mathrm{CFI} \geq 0.97$

\section{Root Mean Square Error of Approximation (RMSEA)}

A good fit exists can be observed when RMSEA value is equal to or lower than 0.05. An adequate fit exists if the value is higher than 0.05 and below 0.08 . Values between 0.08 and 1.00 are considered to be acceptable. RMSEA values over 1 are not acceptable.

RMSEA value in this study is calculated as 0.029. Therefore, a good fit exists.

Table 5: Root Mean Square Error of Approximation (RMSEA)

\begin{tabular}{lcccc}
\hline & RMSEA & LO 90 & HI 90 & PCLOSE \\
\hline Default Model & 0.029 & 0.01 & 0.044 & 0.991 \\
\hline Independence Model & 0.215 & 0.205 & 0.224 & 0 \\
\hline
\end{tabular}

RMSEA $=0.029 \leq 0.05$

\subsection{Hypotheses Testing}

Hypotheses can be accepted according to the analyses performed above. All factors are evaluated depending on the outcomes acquired from the statistical analyses. Quantitative analyses are compared with the previous results acquired from the literature.

\section{Usefulness}

H1: Higher level of usefulness (USF) has a positive effect on use of mobile payment systems.

Usefulness is a powerful aspect influencing mobile payment acceptance. This is in line with the literature findings as it is stated in previous studies (Zhong et al, 2013) (Guo, 2017). The relations path coefficient between usefulness and perceived usefulness is 0.69 . Perceived usefulness $(U)$ has a positive effect 0.58 on behavioral intention (BI) directly. Therefore, $\mathrm{H} 1$ is accepted. Higher level of usefulness (USF) has a positive effect on use of mobile payment systems.

\section{Security}

H2: Higher level of security (SEC) has a positive effect on use of mobile payment systems.

Security and fraud concerns are very common among consumers. They are worried to be exposed to financial and identity theft while using mobile payments. It is vital for service providers to invest more on anti-fraud and security development in order to ensure the prevalence of mobile payments. Otherwise, these issues will be a huge obstacle that prevents mobile payments from further adoption.

The relations path coefficient between security (SEC) and perceived usefulness (U) is 0.29 . Security (SEC) has a positive effect 0.58 on behavioral intention (BI) directly. Therefore, $\mathrm{H} 2$ is accepted. Higher level of security (SEC) has a positive effect on use of mobile payment systems.

Results found in previous literature suggest that the amount of effort put on mobile payment course would be less if the user feels more secure about the solution and the service provider. Therefore, perceived usefulness is directly affected by security (Khalilzadeh et al, 2017). 
However, another study found that subjective security was not a big concern for users and consumers are feeling more comfortable with mobile payments. Therefore, solution providers can spend their resources on other development issues (Pousttchi and Wiedmann, 2007).

\section{Social Influence}

H3: Higher level of social influence (SOC) has a positive effect on attitude towards mobile payment technology acceptance.

The relations path coefficient between social Influence (SOC) and perceived usefulness $(U)$ is 0.27 . Social influence (SOC) has a positive effect 0.58 on behavioral intention (BI) directly. Therefore, H3 is accepted. Higher level of social influence (SOC) has a positive effect on use of mobile payment systems. However, in previous studies there are some cases in which this hypothesis is rejected (Shin, 2009) (Kim et al, 2016).

\section{Attractiveness of Alternatives}

$\mathrm{H} 4$ : Higher level of attractiveness of alternatives (AOA) has a negative effect on use of mobile payment systems.

The relations path coefficient between attractiveness of alternatives (AOA) and Perceived Usefulness $(U)$ is -0.61 . Attractiveness of alternatives (AOA) has a positive effect 0.58 on behavioral intention (BI) directly. Therefore, $\mathrm{H} 4$ is accepted. Higher level of attractiveness of alternatives (AOA) has a negative effect on use of mobile payment systems. Cost factor, which is considered as a part of attractiveness of alternatives in this research was tested previously in literature. Cost's effect on usefulness was found significant (Pham and Ho, 2015) (Slade et al, 2015) (Ooi and Tan, 2016).

\section{Ease of Use}

H5: Higher level of ease of use (EOU) has a positive effect on use of mobile payment systems.

The relations path coefficient between ease of use (EOU) and perceived ease of use (E) is 0.62 . Therefore, H5 is accepted. Higher level of ease of use (EOU) has a positive effect on use of mobile payment systems. This result is parallel with the studies in the literature. Ease of use increases the behavioral intention to use mobile payment systems (Qasim and AbuShanab, 2016) (Liébana-Cabanillas et al, 2017).

Compatibility is also considered as a part of ease of use in this study. In previous literature studies, compatibility has a positive effect both on security and usefulness (Pham and Ho, 2015) (Ramos-de-Luna, 2016) (Ooi and Tan, 2016). It seems that as consumers' lifestyle get more familiar with mobile payments, they tend to feel more secure and find mobile payments more useful. If the user's previous habits are more akin to the experience created by mobile payments, he feels less anxious and more secure to use it (Peng et al, 2012).

\section{Enjoyment}

H6: Higher level of enjoyment (ENJ) has a positive effect on use of mobile payment systems.

The relations path coefficient between enjoyment (ENJ) and perceived ease of use (E) is 0.43 . Therefore, $\mathrm{H} 6$ is accepted. Higher level of enjoyment (ENJ) possesses a positive effect on use of mobile payment systems. In previous studies, there are some cases in which "enjoyment" was observed to affect "ease of use" and "usefulness" (Koenig-Lewis et al, 2015).

\section{New Technology Anxiety}

H7: Higher level of new technology anxiety (NTA) has a negative effect on use of mobile payment systems.

The relations path coefficient between new technology anxiety (NTA) and perceived ease of use (E) is - 0.27 . Therefore, $\mathrm{H7}$ is accepted. Higher level of new technology anxiety (NTA) possesses a negative effect on use of mobile payment systems.

\section{Innovativeness}

H8: Higher level of innovativeness (INV) has a positive effect on use of mobile payment systems.

Innovative people are yet inclined to using new innovations. Therefore, mobile payment usage is a strong field of interest for them. The relations path coefficient between innovativeness (INV) and perceived ease of use (E) is 0.55 . The results obtained in this research is parallel with the literature outcomes (Slade et al, 2015) (Liébana-Cabanillas et al, 2015). Innovative individuals are more inclined to experience new stuff. Mobile payments in this case can be considered as a new technology.

\section{Attitude}

H9: Higher level of attitude has a mediating effect on intention towards mobile payment technology acceptance. 
Attitude acts as a mediator for perceived ease of use (E) and perceived usefulness ( $\mathrm{U})$ with 0.03 on behavioral intention (BI) indirectly.

\section{CONCLUSION AND IMPLICATIONS}

This research provides us with a wider view on mobile commerce. It has shown that mobile payments are a potential mainstream trend for the near future. Common usage of smart mobile devices helps mobile payment solution providers in building new payment channels. Several benefits of the mobile payment value chain have been identified for both technology providers and the consumers. Other findings of this research can be stated as the challenges which the stakeholders are experiencing while trying to extend mobile payment technologies to a wider consumer base. The resistance that prevents consumers from adopting the mobile payment solutions can be observed via this research. Therefore, the results and the variables can be used by service providers who want to launch new mobile payment solutions for similar markets and they can take actions for getting more efficient results accordingly.

Literature review studies in this field have been conducted before several times. However, this research intended to appeal to a space in the literature by presenting a different perspective. It grouped factors from a broader literature and embedded the factors into a modified research model. A mobile payment acceptance model was developed for this study referring to the constructs adopted in other research after a thorough literature review. Some author generated questions were added to the survey such as the one expressing the hygiene feature of mobile payments.

Previous studies in Turkey and around the world have been performed with small groups of respondents. Therefore, their results could not be generalized to the population. This research managed to gather 685 respondents that is higher than the median of the sample size in literature. Mean of the sample size for analysis in previous studies was 465 and the median was 292 .

This research was conducted in a cosmopolitan and technology friendly city Istanbul where all sorts of mobile payment options are available in the market. This is another distinguishing fact for this study since the sample was already widely exposed to the mobile payment technology in their daily lives.

This study was the first research to be conducted on mobile payment acceptance during a pandemic. As social distancing and remote delivery and online purchases became more common for shopping, experimenting mobile payments became more inevitable for consumers. Therefore, the effect of the compulsory usage is reflected to the results of this study in a positive way. Consumers are more familiar with the mobile payment technology henceforth and they easily prefer mobile payments compared to offline alternative methods.

Each market has its own characteristics and consumers have their unique expectations. Convincing potential customers to use new mobile payment solutions requires all stakeholders to work in a highly cooperative manner. The benefits of governments, technology service providers, financial institutions, merchants and network service providers must be considered as much as the consumers' needs.

Consumer needs might either be real or perceived. The fulfilment of these needs determines whether a technology solution will become fully adopted. In emerging markets, the challenge is to make sure new innovations are properly regulated. This involves a support for new product developers too. Governments should assist fintech companies in research and development and marketing of their mobile payment solutions. Otherwise, these start-up companies will have a hard time cooperating with large financial institutions and mobile network operators in equal terms. In developed markets where financial infrastructure is well established, current regulations will more likely play the main role. Already running regulations will cover security issues for mobile payments and new solutions will have a faster go to market period.

There is a strong effect of usefulness on mobile payment usage. Consumers must be convinced that mobile payment methods provide outstanding mobility benefits compared to alternative methods. Otherwise, if the mobile payment process is not more convenient, this will be a big barrier for consumer adoption.

Technology infrastructure is a crucial parameter for motivating the people to use mobile payment systems. The speed and technical high availability reduce the new technology anxiety among users which has an effect on perceived usefulness. As the technical infrastructure gets better, a positive attitude towards mobile payments is created.

Power of alternatives / substitutes that prevent mobile payments to be widely accepted may vary between different markets. Europe, Asia, USA, Africa.

Turkey especially has a very high increasing rate of $4 \mathrm{G}$ adaptation, mobile broadband internet usage and latest mobile devices ownership over the past years. This happens both on the consumer and the merchant sides. The rapid developments provide speed and convenience for all parties involved in mobile payments. 
Ease of use appears to be a vital factor to focus on to improve mobile payment adoption. Developing a more user-friendly interface will definitely increase perceived ease of use as well as perceived usefulness. New generation mobile devices and their features must be considered when developing mobile payment interfaces and mobile apps.

Social influence does not offer a condition to make consumers use mobile payments. People are rather affected by security than their social environment. Social influence is more important during the early stages of technology adoption. However, technology adoption of innovative solutions depends mostly on how easy they can be learned. Trust and security issues play a major role on intention too. But instead of adding extra security layers to the solution, these issues can be overcome by social influence during the early stages.

Because of social influence's effect on intention, social influence contributes to decreasing the perceived security risk. Previous studies suggest that mobile payment service providers should include extra security layers in their solutions to increase user acceptance (Khiaonarong, 2014). Trusted third party mobile security systems are similarly important and suggested in literature for increasing perceived security and therefore increasing user acceptance (Shin, 2009).

These outcomes imply that mobile payment solutions can increase customer loyalty, satisfaction, and revenues. It is possible for mobile payment solutions to provide economic growth and innovation by improving business processes and leading to new service offerings.

This research clarified that security is a main factor that prevents mobile payments from being adopted fast enough. The speed of mobile payment solutions to be available in the market is another issue that slows down mobile payment acceptance. Previous studies in literature suggest that there are several reasons for slow introduction to market. These are mainly; security concerns, lack of infrastructure, high costs, lack standards and regulations.

There are several obstacles to be cleared out for mobile payments to be a mainstream payment option. Several solutions have been tried and failed before. Solution providers, financial institutions, merchants and consumers all have to be in a mutually beneficial relationship. These stakeholders will altogether create the optimum business models. Governments should then license the tested and standardized solutions to successful solution providers to be implemented all around the market.

As a conclusion, the study successfully addressed the gap in the literature by shedding more light onto the factors encouraging and hindering mobile payments' acceptance and utilization challenges with several contributions to the literature, actionable insights for marketing managers and ideas for further research.

Mobile payments have a rapidly growing demand in the market. It is changing the way transactions are carried out both for consumers and businesses. Therefore, it is crucial to study this topic further. The scope can be enhanced to get a better understanding on how consumers perceive mobile payments and what can be done to increase user acceptance.

This research has constraints for reasons such as resource and time limitations. The research took place in a specific time frame, among a specific group of people belonging to a specific culture. Further research can be conducted during another time frame when mobile payments are more commonly used in a different society. Sample size can be enhanced. Additional variables can be discovered and examined. These alternative modifications will probably yield much better results and create better structural equation models. An extensive research can be carried out about the effect of culture on mobile payments acceptance as well.

Several innovations and business models in mobile payments solutions have failed to increase consumer adoption. Universal regulations are still not available for all stakeholders. These obstacles cause fragmented markets with nonstandard solutions. A wider acceptance of mobile payments for consumers is still an issue and further research can help in building better business models and developing optimum solutions.

This research was carried out during a global pandemic in Istanbul. The survey responses were collected between April 2020 and June 2020. Turkey was affected by the pandemic as much as any other country in the world and lockdowns were regular practices during this period. Contactless payments, remote delivery and online purchases were much more preferred compared to offline alternatives. Therefore, it is worth considering executing similar studies when the pandemic is totally over to see the possible effects of the extraordinary pandemic period.

\section{ACKNOWLEDGEMENTS}

I would like to mention my deepest gratitude to Prof. Dr. Murat FERMAN who led me forward in all stages of my research. 


\section{REFERENCES}

Alexandre, C., Mas, I., Radcliffe, D., (2011). Regulating new banking models to bring financial services to all. Challenge, 54(2), $116-134$.

Amoroso, D., Watanabe, R. M., (2011). Building a research model for mobile wallet consumer adoption: the case of mobile suica in Japan. Journal of Theoretical and Applied Electronic Commerce Research, 7(1), 94-110.

Antovski, L., Gusev, M., (2003). M-Payments. 25th International Conference of Information Technology Interfaces, Cavtat, Croatia.

Au, Y. A., Kauffman, R., (2006). The economics of mobile payments: understanding stakeholder issues for an emerging financial technology application, 234, 24.

Bailey, A., Pentina, I., Mishra, A. S., Ben Mimoun, M. S., (2017). Mobile payments adoption by us consumers: an extended TAM. International Journal of Retail and Distribution Management, 45(6), 626-640.

Bohle, K., M. Krueger, et al. (2000). Electronic payment systems: strategic and technical issues, December 3, 2000, Seville, Electronic Payment Systems Observatory (ePSO).

Bohle, K., Krueger, M., (2001). Payment culture matters- a comparative EU-US perspective on internet payments, January 2001, Electronic Payment Systems Observatory (ePSO).

Carlsson, C., (2001). Mobile commerce: core issues, products and services. Panel at the Bled Electronic Commerce Conference, Bled, Slovenia.

Clemons, E. K., D. C. Croson, et al. (1997). Reengineering money: the mondex stored value card and beyond. International Journal of Electronic Commerce, 1(2), 5-31.

Dahlberg, T., Mallat, N., (2006). Mobile payment market and research- past, present and future. University of Technology, Sydney.

Davis, F. D., (1993). User acceptance of information technology: system characteristics, user perceptions and behavioral impacts. International Journal of ManMachine Studies, 38(3), 475-487.

Devkishin, K. R., Rizvi, A. H., Akre, V. L., (2013). Analysis of factors affecting the online shopping behavior of consumers in U.A.E. International Conference on Current Trends in Information Technology (CTIT), 2013, Dubai: IEEE, 220-225.

Ding, M. S., Hampe, J. F., (2003). Reconsidering the challenges of mpayments: a roadmap to plotting the potential of the future mcommerce market, 16th Bled eCommerce Conference, June 9-11, 2003, Bled, Slovenia.

Diniz, H., (2011). Mobile money and payment: a literature review based on academic and practitioner-oriented publications (2001-2011), December 3, 2011, Shanghai: Proceedings of SIG GlobDev Fourth Annual Workshop.

Dornan, A., (2001). The essential guide to wireless communications applications: from cellular systems to WAP and M-commerce. Prentice Hall, Upper Saddle River, NJ, ISBN: 9780130097187.

Fishbein, M., Ajzen, I., (1975). Belief, attitude, intention and behavior: an introduction to theory and research. Addison-Wesley, Reading, MA, ISBN: 9780201020892

Guo, K., (2017). An empirical examination of initial use intention of mobile payment. Boletín Técnico, 55(10).

Huh, J. H., Verma, S., Rayala, S. S., Bobba, R., Beznosov, K., Kim, H. (2016). I don't use apple pay because it's less secure - perception of security and usability in mobile tap-and-pay. USEC'16, February 21, 2016, San Diego, CA, USA.

ING Bank International Researches. (2016). Mobile Thinking 2017 [online], https://think.ing.com/uploads/reports/IIS_Mobile_Banking_2017_Newer_Technologies_FINAL.pdf [Date Accessed: August 4, 2020].

Javalgi, R., Ramsey, R., (2001). Strategic Issues of e-commerce as an alternative global distribution system. International Marketing Review, 18(4), 376-391.

Jayawardhena, C., Foley, P., (1998). Overcoming constraints on electronic commerce: internet payment systems. Journal of General Management, 24(2), 19-35.

Karnouskos S., Fokus F. (2004). Mobile payment: a journey through existing procedures and standardization initiatives. IEEE, 6(4), $44-46$.

Khalilzadeh, J., Ozturk, A. B., Bilgihan, A., (2017). Security-related factors in extended UTAUT model for NFC based mobile payment in the restaurant industry. Computers in Human Behavior, 70, 460-474.

Khiaonarong, T., (2014). Oversight issues in mobile payments. 2014 International Monetary Fund, 14(123).

Koenig-Lewis, N., Marquet, M., Palmer, A., Zhao, A. L. (2015). Enjoyment and social influence: predicting mobile payment adoption. Service Industries Journal, 35(10), 537-554.

Kruger, M., (2001). The future of m-payments: business options and policy issues, August 2001, Seville, Electronic Payment Systems Observatory (ePSO). 
Liébana-Cabanillas, F., Ramos de Luna, I., Montoro-Ríos, F. J., (2015). User behaviour in QR mobile payment system: the QR payment acceptance model. Technology Analysis and Strategic Management, 27(9), 1031-1049.

Liébana-Cabanillas, F., Ramos de Luna, I., Montoro-Ríos, F. (2017). Intention to use new mobile payment systems: a comparative analysis of SMS and NFC payments. Economic Research, 30(1), 892-910.

Liébana-Cabanillas, F., Muñoz-Leiva, F., Sánchez-Fernández, J., (2018). A Global approach to the analysis of user behavior in mobile payment systems in the new electronic environment. Service Business, 12(1), 25-64.

Lim A.S., (2007). Inter-consortia battles in mobile payments standardisation. Electronic Commerce Research and Applications, 7(2), 202213.

Lowry, C., (2016). What's in your mobile wallet? an analysis of trends in mobile payments and regulation. Federal Communications Law Journal, 2(68), 353-384

Mallat, N., (2007). Exploring consumer adoption of mobile payments - a qualitative study. Journal of Strategic Information Systems, 16 (4), 413-432.

Misra S.K., Wickamasinghe N. (2004). Security of mobile transaction: a trust model. Electronic Commerce Research, 4(4), 359-372.

Murthy, S. R, Mani, M., (2013). Discerning rejection of technology. Sage Open, 3(2), 1-10.

Oliveira, T., Thomas, M., Baptista, G., Campos, F., (2016). Mobile payment: understanding the determinants of customer adoption and intention to recommend the technology. Computers in Human Behavior, 61, 404-414.

Ondrus, J., Pigneur, Y. (2005). A disruption analysis in the mobile payment market. 38th Hawaii International Conference on System Sciences, January 3-6, 2005, Hawaii, USA.

Ooi, K., Tan, G. W., (2016). Mobile technology acceptance model: an investigation using mobile users to explore smartphone credit card. Expert Systems with Applications, 59, 33-46.

Peng, R., Xiong, L., Yang, Z., (2012). Exploring tourist adoption of tourism mobile payment: an empirical analysis. Journal of Theoretical and Applied Electronic Commerce Research, 7(1), 21-33.

Pham, T. T. T., Ho, J. C. (2015). The effects of product-related, personal-related factors and attractiveness of alternatives on consumer adoption of NFC-based mobile payments. Technology in Society, 43, 159-172.

Poushter J., (2016). Smartphone ownership and internet usage continues to climb in emerging economies. [online], http://www.pewglobal.org/2016/02/22/smartphone-ownership-and-internet-usagecontinues-to-climb-in-emerging-economies/ [Date Accessed: August 21, 2020].

Pousttchi, K., Wiedemann, D. G., (2007). What influences consumers' intention to use mobile payments? LA Global Mobility Round Table, $1-16$.

Qasim, H., Abu-Shanab, E., (2016). Drivers of mobile payment acceptance: the impact of network externalities. Information Systems Frontiers, 18(5), 1021-1034.

Ramos-de-Luna, I., Montoro-Ríos, F., Liébana-Cabanillas, F., (2016). Determinants of the intention to use NFC Technology as a payment system: an acceptance model approach. Information Systems and e-Business Management, 14(2), 293-314.

Rogers, E.M., (1995). Diffusion of innovations. 4th Edition, The Free Press, New York, ISBN: 0028740742

Shin, D., (2009). Towards an understanding of the consumer acceptance of mobile wallet. Computers in Human Behavior, 25(6), 13431354.

Shon, T. H., Swatman, P. M. C., (1997). Effectiveness criteria for internet payment systems. First Pacifica-Asia Workshop on Electronic Commerce, April 5, 1997, Brisbane, Australia.

Slade, E. L., Dwivedi, Y. K., Piercy, N. C., Williams, M. D., (2015). Modelling consumers' adoption intentions of remote mobile payments in the United Kingdom: extending UTAUT with innovativeness, risk, and trust. Psychology and Marketing, 32(8), 860-873.

Slade, E., Williams, M., Dwivedi, Y., Piercy, N. (2015). Exploring Consumer Adoption of Proximity Mobile Payments. Journal of Strategic Marketing, 23(3), 209-223.

Turban, E., D. King, et al. (2002). Electronic commerce 2002: a managerial perspective. Pearson Education, Upper Saddle River, NJ, ISBN: 978-0130653017.

Venkatesh, V., (2000). Determinants of perceived ease of use: integrating control, intrinsic motivation, and emotion into the technology acceptance model. Information Systems Research, 11(4), 342-365.

Venkatesh, V., Thong, J. Y., Xu, X., (2012). Consumer acceptance and use of information technology: extending the unified theory of acceptance and use of technology. MIS Quarterly, 36(1), 157-178.

Wang, Y., Hahn, C., Sutrave, K., (2016). Mobile payment security, threats, and challenges. MobiSecServ, 2016, 2nd Int'I Conference February 26-27, 2016, Gainesville, FL, IEEE. 
Weiss, K., (2011). Mobile payments, digital wallets and tunnel vision. Biometric Technology Today, 2011(10), 8-9.

Yang, K., Forney, J. C., (2013). The moderating role of consumer technology anxiety in mobile shopping adoption: differential effects of facilitating conditions and social influences. Journal of Electronic Commerce Research, 14(4), 334-347.

Yang, S., Lu, Y., Gupta, S., Cao, Y., Zhang, R., (2012). Mobile payment services adoption across time: an empirical study of the effects of behavioral beliefs, social influences, and personal traits. Computers in Human Behavior, 28, 129-142.

Yoris, A., Aua, R., Kauffman, J., (2008). The economics of mobile payments: understanding stakeholder issues for an emerging financial technology application. Electronic Commerce Research and Applications, 7(2), 141-168.

Zhong, J., Dhir, A., Nieminen, M., Hämäläinen, M., Laine, J., (2013). Exploring consumer adoption of mobile payments in China. Proceedings of the 17th International Academic MindTrek Conference, Making Sense of Converging Media, October 01-04, 2013, Tampere, Finland, New York: Association for Computing Machinery, 318-325.

Zmijewska, A., (2005). Evaluating wireless technologies in mobile payments - a customer centric approach. 4th International Conference on Mobile Business, July 11-13, Sydney, Australia, New York: IEEE, 354-362. 